\title{
Penerapan Metode Pengembangan Sistem Extreme Programing (XP) Pada Aplikasi Presensi Karyawan dengan QR Code
}

\author{
Qubaila Ega Fazrin', Tuti Lisnawati², Sri Nurhayati', Juli Budi Satya'2, Dedy Alamsyah ${ }^{3}$," \\ ${ }^{1}$ Komputerisasi Akuntansi, AMIK Citra Buana Indonesia, Sukabumi, Indonesia \\ ${ }^{2}$ Manajemen Informatika, AMIK Citra Buana Indonesia, Sukabumi, Indonesia \\ ${ }^{3}$ Teknik Informatika, Universitas Muhammadiyah Tangerang, Tangerang, Indonesia \\ Email: 1 qubaila.fes@gmail.com, ${ }^{2}$ tutilisnawati448@ gmail.com, ${ }^{1}$ sri.amikcbi@gmail.com, ${ }^{2}$ julisatya321@gmail.com, \\ 3,*dedy.alamsyah@umt.ac.id \\ Email Penulis Korespondensi: dedy.alamsyah@umt.ac.id \\ Submitted: 12/12/2021; Accepted: 25/12/2021; Published: 31/12/2021
}

\begin{abstract}
Abstrak-Presensi merupakan proses mencatat dan mengelola data kehadiran yang dilakukan sehari-hari pada waktu jam kerja pada setiap perusahaan. Kesalahan dalam pencatatan kehadiran karyawan sangat berpengaruh terhadap penghasilan karyawan. Maka, kevalidan dalam pencatatan sangat dibutuhkan. Sistem pencatatan kehadiran secara manual rawan kesalahan dan rekapitulasinya membutuhkan waktu yang lama. Untuk mengatasi hal tersebut maka dibutuhkan pengembangan sistem presensi yang dapat dilakukan dengan cepat dan menghasilkan laporan yang valid terkait waktu masuk dan pulang. Pada penelitian ini akan dikembangkan aplikasi presensi menggunakan scanning $Q R$ Code dengan menerapkan metode Extreme Programming (XP). Metode extreme programming (XP) menawarkan tahapan dalam waktu relatif singkat. Berdasarkan pengujian black box testing, aplikasi presensi $Q R$ Code yang dihasilkan sesuai dengan kebutuhan pengguna dengan nilai uji fungsionalitas sebesar $100 \%$.
\end{abstract}

Kata Kunci: Extreme Programming; XP; QR Code; Presensi; Karyawan

Abstract-Attendance is the process of recording and managing attendance data that is carried out daily during working hours at each company. Errors in recording employee attendance greatly affect employee earnings. So, the validity of the recording is needed. The attendance recording system manually is error-prone and its recapitulation takes a long time. To overcome this, it is necessary to develop an attendance system that can be done quickly and produce valid reports regarding the time of entry and exit. In this study, a presence application will be developed using $Q R$ Code scanning by applying the Extreme Programming (XP) method. The extreme programming (XP) method offers stages in a relatively short time. Based on black box testing, the generated $Q R$ Code presence application is in accordance with user needs with a functionality test value of $100 \%$.

Keywords: Extreme Programming; XP; QR Code; Presence; Employee

\section{PENDAHULUAN}

Dewasa ini teknologi memiliki peran penting dalam membantu dan meringankan pekerjaan manusia. Teknologi juga berperan penting dalam membantu perusahaan, khsusnya dalam pengambilan keputusan [1][2]. Luaran sistem dapat menjadi dasar pengambil keputusan untuk menentukan langkah startegis perusahaan [3][4]. Maka, sudah menjadi suatu kewajiban bagi perusahaan untuk menerapkan sistem informasi. Tidak terkecuali pada sistem pencatatan kehadiran atau presensi. Presensi merupakan proses mencatat dan mengelola data kehadiran yang dilakukan seharihari pada waktu jam kerja pada setiap perusahaan [5]. Hasil dari proses ini akan digunakan Human Resource Department (HRD) untuk menetukan berbagai hal, salah satunya penggajian. Kesalahan dalam pencatatan kehadiran karyawan sangat berpengaruh terhadap penghasilan karyawan. Maka, kevalidan dalam pencatatan sangat dibutuhkan. Sistem pencatatan kehadiran secara mnaual rawan kesalahan dan rekapitluasinya membutuhkan waktu yang lama [6]. Maka dibutuhkan sistem secara otomatis yang dapat melakukan presensi kehadiran karyawan. Saat ini telah beredar teknologi Quick Response Code atau yang biasanya disingkat $Q R$ Code. QR Code berupa gambar dua dimensi yang dapat menyajika bermacam jenis informasi dengan cepat [7]. Untuk membuk $Q R$ Code membutuhkan media berupa scanner atau pemindaian berupa handphone ataupun smartphone. $Q R$ Code memiliki kemampuan penyimpanan hingga 2089 digit atau 4289 karakter [8]. Inilah yang menyebakan $Q R$ Code mampu menampilkan teks pada pengguna. $Q R$ Code dinilai lebih praktis jika dibandingkan dengan penggunaan barcode [9]. Ini dipengaruhi oleh kemampuanya dalam penyimpanan data. $Q R$ Code berisi citra dengan titik-titik hitam dan putih yang tersusun dalam bentuk kotak, dan setiap elemennya memiliki makna tertentu. $Q R$ Code dapat discan melalui smartphone dan menampilkan data atau informasi yang ada didalamnya. Teknologi $Q R$ Code ini dapat dimanfaatkan untuk pengembangan sistem presensi secara komputerisasi.

Pengembangan sistem merupakan sebuah kegiatan dalam untuk menyempurnakan sistem yang sebelumnya telah ada [10]. Ketika melaksanakan pengembangan sistem dapat dimungkinkan terjadi adanya perubahan yang berdampak pada tim pengembang perangkat lunak. Maka dibutuhkan metode dalam melakukan pengembangan sistem agar pengembangan yang dilakukan lebih terencana dengan baik [11]. Metode pengembangan sistem merupakan kerangka pijakan utama untuk pengembangan aplikasi agar dapat membangun suatu sistem yang sesuai dengan kebutuhan pengguna dan organisasi [12]. Dalam pengembangan sistem alangkah baiknya dilakukan melalui tahapan yang telah direncakan dan jelas runutannya [13]. Terdapat beberapa metodologi pengembangan sistem yang dapat digunakan, antara lain: waterfall, RAD, prototype serta agile development. Metode agile development merupakan metodologi yang dianggap lebih efisien dan fleksibel [14]. Agile software development yaitu metode software deevelopment berdasarkan pada iterasi, di mana kebutuhan pada setiap tahapan dan solusi yang ditawarkan berbasis 
pendekatan kerjasama pengembang [15]. Extreme Programming (XP) merupakan satu diantara beberapa metode agile development yang cocok dengan pengembangan sistem cepat dan dapat digunakan dalam menyesuaikan persyaratan. $\mathrm{XP}$ adalah pengembangan sistem yang sasarannya yaitu agar dapat membangun melalui persyaratan atau kebutuhan yang belum matang atau belum jelas karena masih adanya perubahan-perubahan terhadap kebutuhan yang sangat cepat dan dengan tim yang tidak terlalu besar [16]. Metode ini dapat mengatasi perubahan berdasarkan desain dan fitur dengan penanganan yang fleksibel.

Beberapa penelitian pengembangan sistem yang telah menggunakan XP dianggap telah berhasil dan berjalan dengan baik. Penelitian terdahulu, mengenai penerapan metode XP yang digunakan untuk perancangan sistem perhitungan kuota SKS mengajar dosen [16]. Dalam penelitian ini memperlihatkan bahwasanya sistem dapat berjalan dan berfungsi dengan baik, hal ini dibuktikan dengan hasil pengujian black box testing yang menunjukkan bahwa sistem telah sesuai dengan kebutuhuan. Penelitian selanjutnya yaitu penelitian mengenai penerapan XP dalam pengembangan aplikasi pengelolaan surat keterangan kependudukan [17]. Pada penelitian ini menunjukkan hasil bahwa pendekatan yang diajukan dapat diimplementasikan dalam membangun aplikasi sederhana yang tidak membutuhkan proses yang diulang-ulang. Pengujian yang dilakukan dengan black-box testing memperlihatkan bahwa XP menghasilkan sistem yang berfungsi dengan baik. Penelitian lainnya, mengeni penerapan pendekatan XP pada $e$ commerce berbasis $m$-commerce [18]. Pada penelitian ini memperlihatkan bahwa teknik pendekatan menggunakan XP dalam setiap tahapnya memberikan percepatan pengembangan pada setiap perubahan yang diinginkan oleh pengguna tanpa adanya batasan.

Tujuan dari penelitian ini adalah mengembangan sistem presensi karyawan dengan $Q R$ Code menggunakan metode pengembangan sistem Extreme Programming (XP). Pendekatan XP digunakan agar dapat menghasilkan aplikasi yang cepat dengan kelebihan dapat menyesuaikan kebutuhan pengguna. Metode XP memiliki kemampuan responsif terhadap perubahan. Pada pengembangan sistem XP terdapat iterasi yang bisa dilakukan berulang kali sesuai dengan kebutuhan. Sistem yang dikembangkan berbasis web dengan menggunakan teknologi QR Code agar karyawan dapat melakukan presensi dengan menggunakan smarphonenya dengan menscannya kedalam sistem. Dengan cara ini presensi dapat dilakukan dengan cepat dan pelaporan dapat dilakukan dengan valid.

\section{METODOLOGI PENELITIAN}

Penelitian ini menggunakan metodologi pengembangan sistem yaitu Extreme Programming (XP). Extreme programming (XP) merupakan metodologi pengembangan agile software development methodologies yang memiliki fokus pada pengkodean (coding) yang merupakan aktivitas utama dalam semua tahapan pada siklus pengembangan perangkat lunak [19]. XP merupakan metode yang memiliki tingkat responsif yang baik terhadap perubahan [12]. Dalam metode XP terdapat pengulangan yang bisa dilakukan berulang kali sesuai dengan kebutuhan. Kelebihan dari metode XP juga yaitu memberikan tawaran tahapan dalam waktu yang singkat dan berulang untuk bagian-bagian yang berbeda sesuai dengan fokus yang akan dicapai. Tahapan pengembangan perangkat lunak dengan XP yaitu: planning (perencanaan), design (perancangan), coding (pengkodean) dan testing (pengujian) [20]. Tahapan-tahapan XP dapat dilihat pada gambar 1:

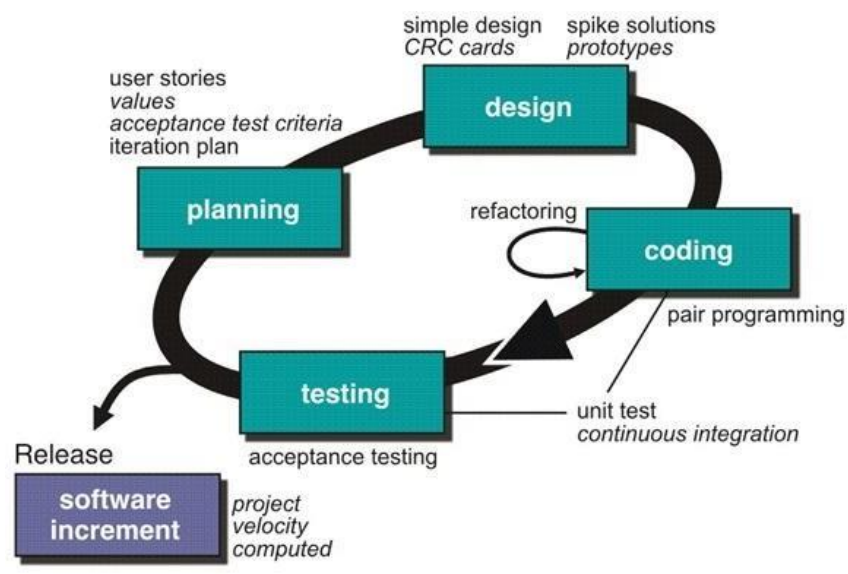

Gambar 1. Tahapan Metode Extreme Programming (XP)

Berdasakan gambar 1, maka runtunan dalam metodologi pengembangan sistem Extreme Programming (XP) adalah sebagai berikut:

1) Planning (Perencanaan): Tahap perencanaan dimulai dari memahami konteks bisnis dari aplikasi, mendefinisikan output, fitur pada aplikasi, fungsi dari aplikasi, serta alur pengembangan aplikasi tersebut. Dapat dikatakan juga bahwa tahapan ini menentukan fungsionalitas keseluruhan yang akan dikembangkan dalam sistem [21]. 
2) Design (Perancangan): Pada tahap perancangan, fokus kegiatan adalah merancang aplikasi secara sederhana, alat untuk merancang pada tahap ini menggunakan use case diagram.

3) Coding (Pengkodean): Coding atau pengkodean merupakan kegiatan menerjemahkan perancangan dalam bahasa pemrograman yang dikenali oleh komputer [22]. Pada penelitian ini, pengkodean dilakukan dengan menggunakan bahasa pemrograman PHP dengan compailer Sublime Text 3 dan database MySQL.

4) Testing (Pengujian): Sistem yang telah dibangun harus diuji terlebih dahulu untuk dapat menemukan kesalahan kesalahan [23]. Sistem diuji menggunakan pengujian black box testing. Pengujian black box merupakan pengujian sistem dari sisi fungsionalitasnya atau kegunaan sistem. Pada pengujian ini akan dilakukan uji input dan output dari sistem.

\section{HASIL DAN PEMBAHASAN}

Aplikasi presensi menggunakan $Q R$ Code ini dikembangan dengan metodologi XP, dari tiap tahapan yang dilakukan, berikut merupakan hasil pengembangan aplikasinya.

\subsection{Planning (Perencanaan)}

Tahapan perencanaan bertujuan untuk mengumpulkan informasi terkait kebutuhan sistem yang akan dikembangkan. Informasi yang telah dikumpulkan lalu disusun dalam bentuk analisa kebutuhan fungsional. Kebutuhan fungsional diperlukan untuk mengetahui fitur apa saja yang tedapat di dalam sistem. Kebutuhan fungsional dari aplikasi presensi QR Code adalah sebagai berikut :

1. Sistem akan digunakan oleh admin

2. Admin harus melakukan login terlebih dahulu sebelum masuk ke dalam sistem dengan memasukkan email dan password

3. Setelah masuk ke dalam sistem, admin akan mengelola data karyawan dengan menginpukan NIK dan Nama karyawan

4. Setelah data karyawan berhasil disimpan, admin dapat melakukan generate $Q R$ Code melalui form generate

5. Setelah $Q R$ Code berhasil di generate berdasarkan NIK yang diinput, secara opsional admin dapat mencetak $Q R$ Code tersebut

6. $Q R$ Code yang sudah berhasil di generate akan digunakan untuk presensi masuk dan pulang oleh karyawan melalui form scan $Q R$ Code

7. Data karyawan masuk dan pulang akan tercatat ke dalam form data presensi

\subsection{Design (Perancangan)}

Tahapan perancangan pada aplikasi presensi $Q R$ Code ini menggunakan salah satu diagram UML yaitu use case diagram. Use case diagram ini akan menggambarkan interaksi antara pengguna aplikasi yaitu admin dengan fitur-fitur yang ada pada sistem. Desain use case diagram dapat dilihat pada gambar 2.

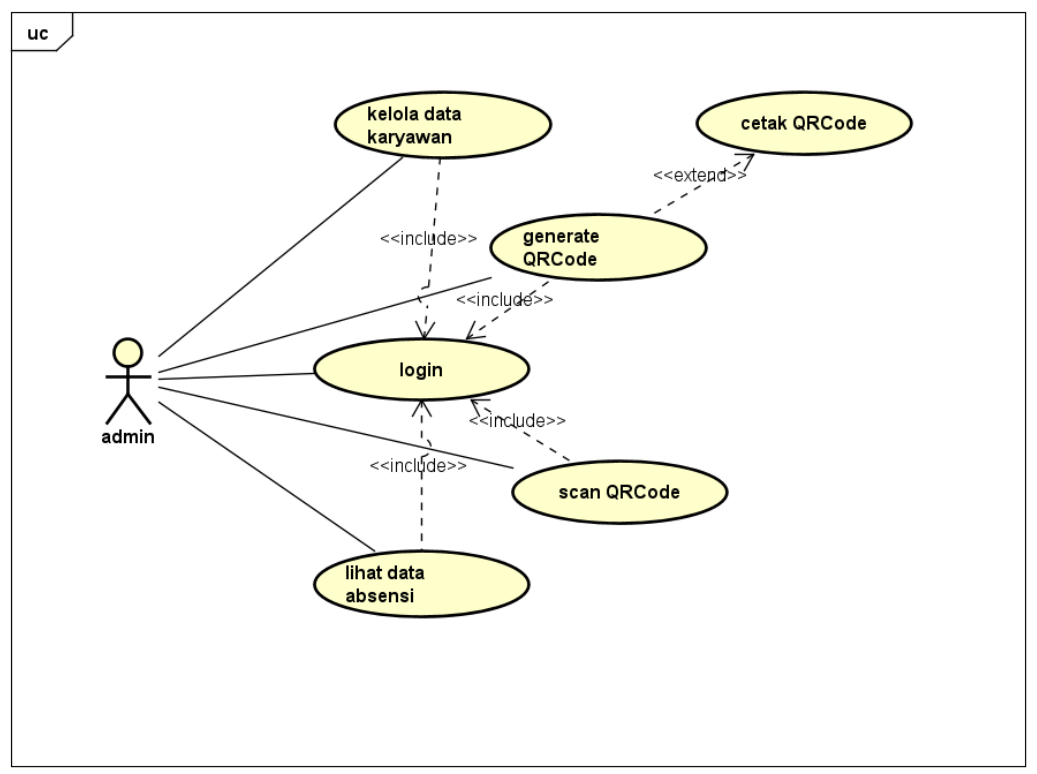

\subsection{Coding (Pengkodean)}

Gambar 2. Use Case Diagram Sistem Presensi $Q R$ Code

Setelah tahap perancangan, selanjutnya akan diimplementasikan dalam bentuk pengkodean program. Pengkodean program pada aplikasi presensi QR Code ini menggunakan Bahasa pemrograman PHP dengan compiler Sublime Text 3 dan database MySQL. Aplikasi dibangun berdasarkan kebutuhan fungsional yang telah ditetapkan. Sesuai dengan 
Building of Informatics, Technology and Science (BITS)

Volume 3, No 3, December 2021, Page 164-170

ISSN 2684-8910 (media cetak)

ISSN 2685-3310 (media online)

DOI 10.47065/bits.v3i3.1018

kebutuhan fungsional, admin dapat melanjutkan ke dalam sistem apabila telah melakukan login, form inputan login dapat dilihat pada gambar 3 .

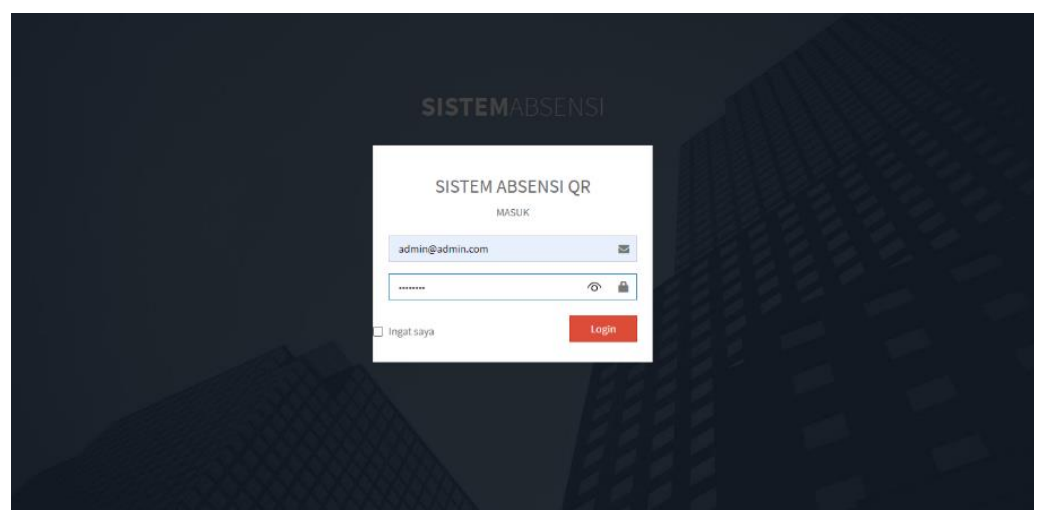

Gambar 3. Halaman Login Sistem Presensi $Q R$ Code

Setelah berhasil login, admin akan masuk ke dalam dashboard sistem. Terlihat pada dashboard ada beberapa fitur sistem yang tersedia yaitu, menu Data, Dapatkan QR, Scan QR, dan Result. Menu data berisi form inputan data karyawan, menu Dapatkan QR berisi form inputan NIK karyawan lalu generate QR, menu Scan QR berisi form yang dapat melakukan pembacaan QR melalui kamera, dan menu Result berisi data presensi karyawan. Tampilan dashboard sistem dapat dilihat pada gambar 4.

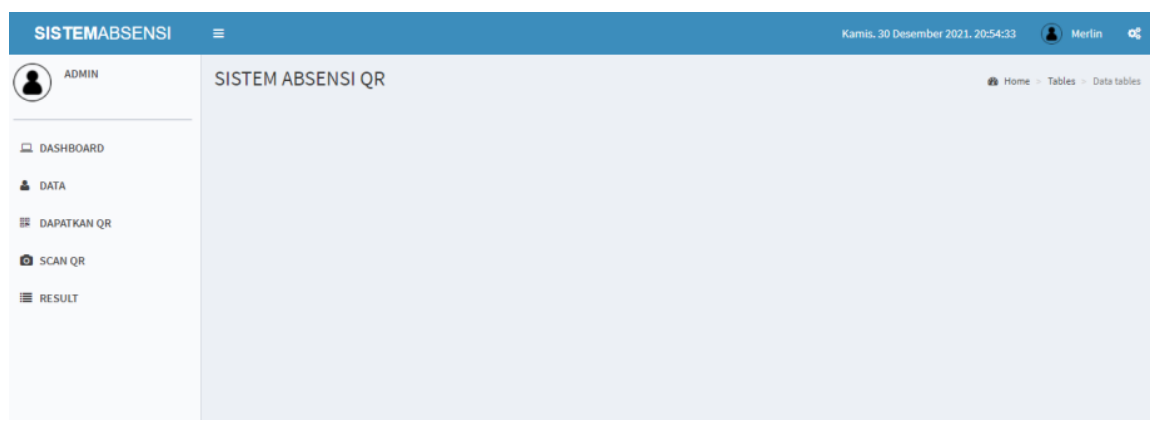

Gambar 4. Halaman Dashboard Sistem Presensi $Q R$ Code

Form inputan data karyawan memerlukan inputan berupa NIK dan Nama Karyawan. Pada tabel data karyawan juga terdapat beberapa tombol aksi seperti edit dan hapus data karyawan. Tampilan form data karyawan dapat dilihat pada gambar 5 .

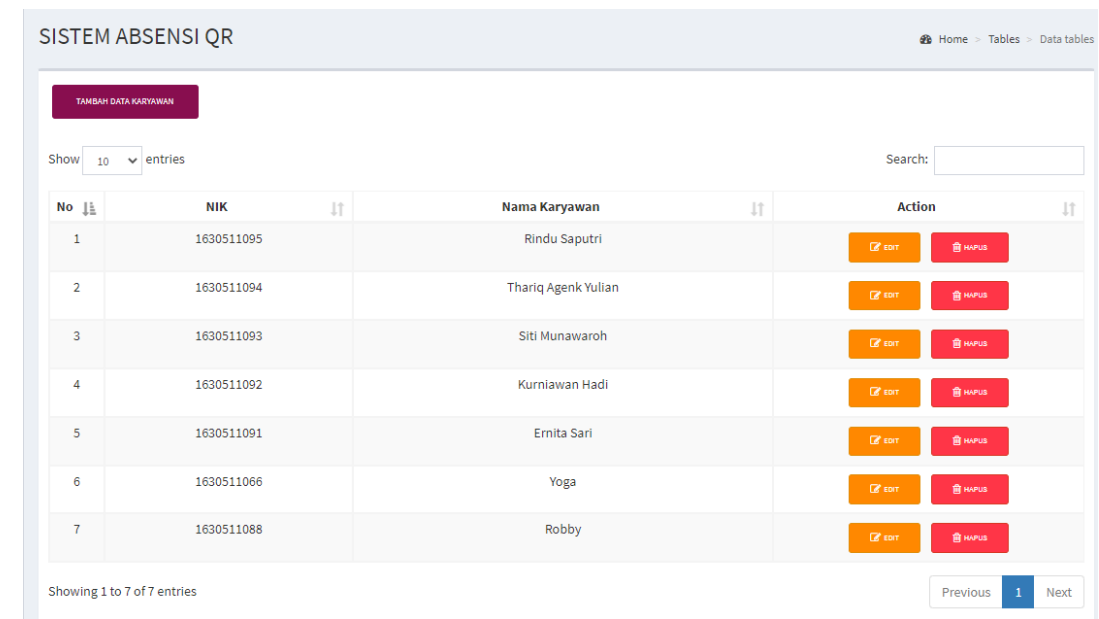

Gambar 5. Halaman Kelola Data Karyawan

Setelah data karyawan berhasil diinputkan, selanjutnya karyawan akan menerima $Q R$ Code dari halaman generate $Q R$ Code. Untuk mendapatkan hasil generate, admin perlu menginputkan NIK pada form, lalu menekan tombol Submit. $Q R$ Code yang tampil dapat dicetak dengan menekan tombol Print. Tampilan form Generate $Q R$ Code dapat dilihat pada gambar 6 . 
Building of Informatics, Technology and Science (BITS)

Volume 3, No 3, December 2021, Page 164-170

ISSN 2684-8910 (media cetak)

ISSN 2685-3310 (media online)

DOI 10.47065/bits.v3i3.1018

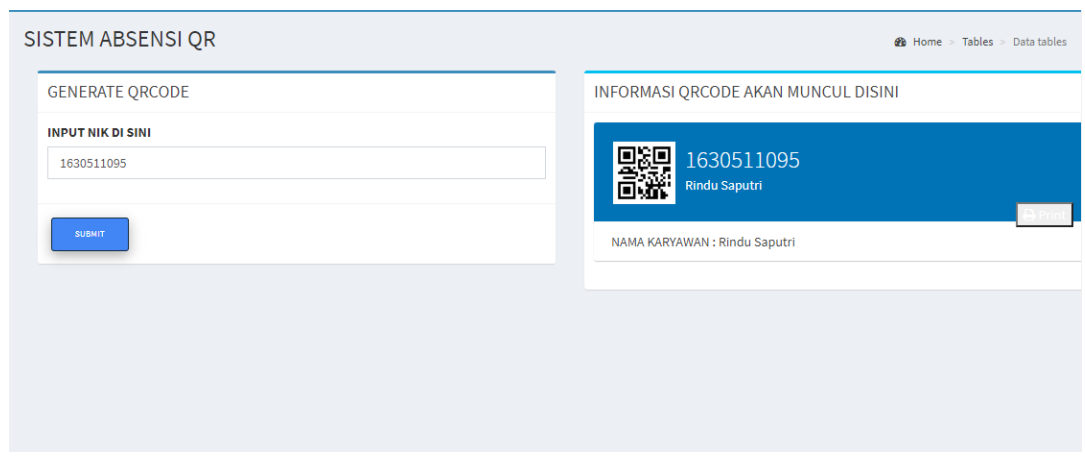

Gambar 6. Halaman Generate $Q R$ Code

Jika admin menekan tombol Print, maka sistem siap mencetak $Q R$ Code hasil generate. Tampilan cetak $Q R$ Code dapat dilihat pada gambar 7.

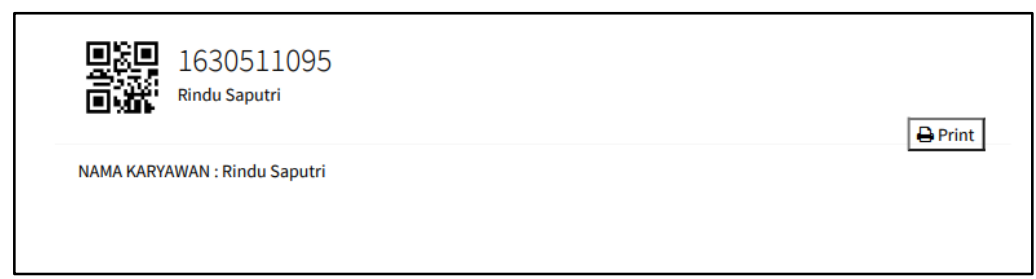

\section{Gambar 7. Halaman Cetak $Q R$ Code}

Form selanjutnya merupakan form scan $Q R$ Code yang merupakan halaman penting dalam sistem presensi ini. Pada form ini terdapat bagian yang terintegrasi dengan kamera yang ada pada PC. Kamera akan membaca $Q R$ Code karyawan yang diarahkan ke depan kamera. Per hari $Q R$ Code karyawan akan dibaca sebanyak dua kali, yaitu pada saat masuk dan pada saat pulang. Tampilan form scan $Q R$ Code dapat dilihat pada gambar 8.

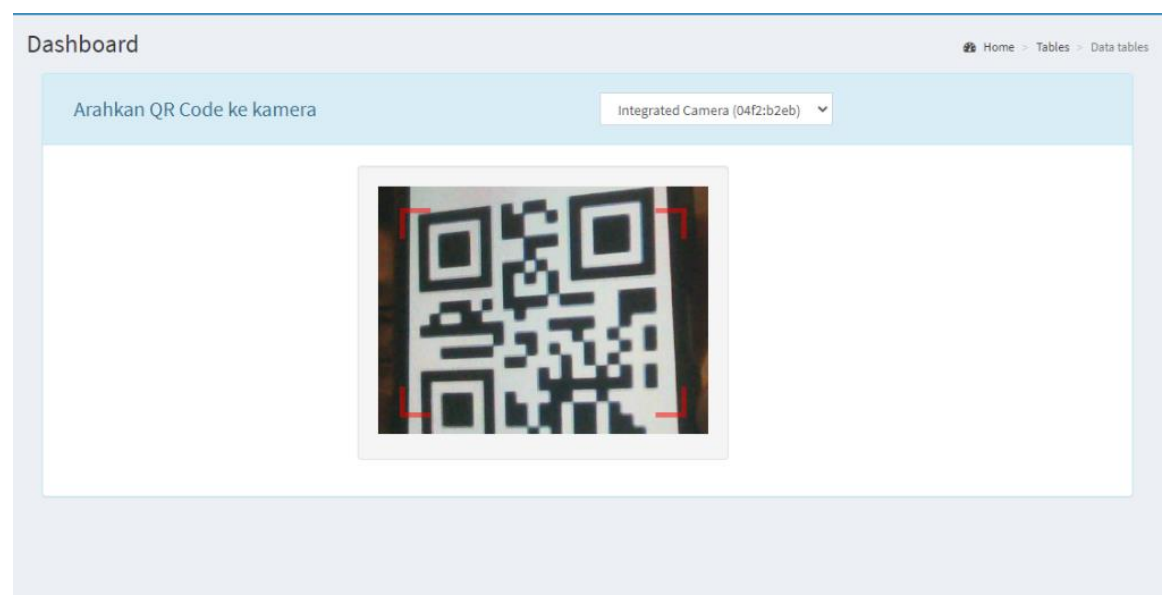

Gambar 8. Halaman Scan $Q R$ Code

Pada saat scan pertama, maka data yang akan masuk ke dalam sistem adalah jam masuk karyawan, tampilan data karyawan masuk dapat dilihat pada gambar 9.

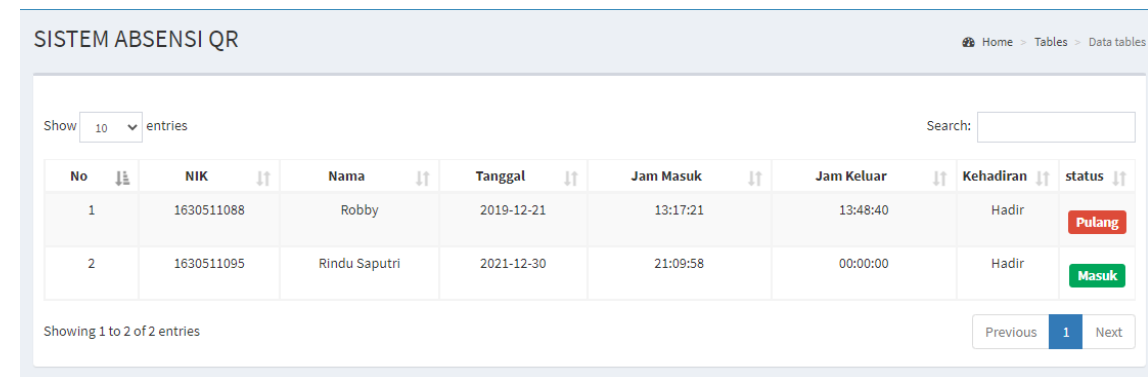

Gambar 9. Halaman Data Karyawan Masuk

Pada saat scan $Q R$ Code kedua kali, maka data yang akan masuk ke dalam sistem adalah jam keluar karyawan, tampilan data karyawan pulang dapat dilihat pada gambar 10. 


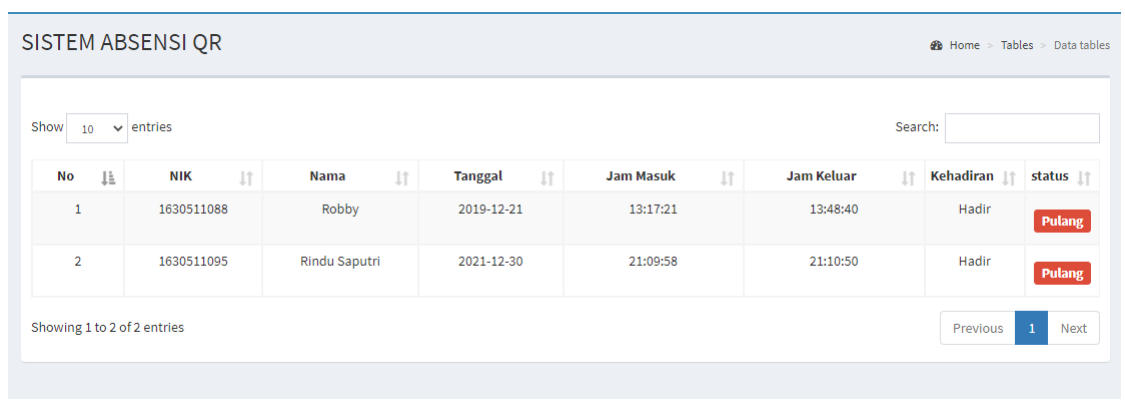

Gambar 10. Halaman Data Karyawan Pulang

\subsection{Testing (Pengujian)}

Sebelum aplikasi presensi $Q R$ Code ini digunakan, tahapan selanjutnya adalah melakukan pengujian terhadap sistem. Sistem diuji menggunakan pengujian black box testing. Pengujian black box merupakan pengujian sistem dari sisi fungsionalitasnya atau kegunaan sistem. Pada pengujian ini akan dilakukan uji input dan output dari sistem. Terdapat 12 butir pertanyaan terkait uji fungsionalitas dari aplikasi presensi $Q R$ Code ini yang diujikan kepada 5 responden bidang IT. Hasil dari pengujian fungsionalitas sistem menggunakan black box testing ini sebesar $100 \%$ sistem menghasilkan input dan output yang sesuai dengan kebutuhan.

\section{KESIMPULAN}

Berdasarkan penelitian yang telah dilakukan, aplikasi presensi $Q R$ Code ini dapat mempermudah karyawan dalam melakukan presensi masuk dan pulang hanya dengan melakukan scanning barcode yang dimiliki setiap karyawan ke dalam sistem. Sistem dapat mencatat jam masuk dan jam pulang karyawan secara realtime, sehingga pelaporan presensi karyawanpun menjadi valid. Dari paparan tersebut, maka dapat disimpulkan bahwa metode Extreme Programming (XP) dapat menghasilkan aplikasi presensi $Q R$ Code yang sesuai dengan kebutuhan, hal ini juga berdasarkan hasil uji fungsionalitas sistem menggunakan pengujian black box testing yang bernilai $100 \%$.

\section{REFERENCES}

[1] R. Destriana, R. Taufiq, F. Paweloi, M. F. Hidayatullah, and W. Algadri, "Analisa dan Perancangan Sistem Informasi EBisnis Menggunakan SWOT Analisis Pada Usaha Kecil Menengah Berbasis Web E-Commerce," in Proceeding SENDIU 2020, 2020, pp. 978-979.

[2] M. Melinda, R. I. Borman, and E. R. Susanto, "Rancang Bangun Sistem Informasi Publik Berbasis Web (Studi Kasus : Desa Durian Kecamatan Padang Cermin Kabupaten Pesawaran)," J. Tekno Kompak, vol. 11, no. 1, p. 1, 2018.

[3] R. Destriana, "Evektivitas Kinerja IT Support Menggunakan Fungsi Service Desk Sebagai SIngle Point of Contact (SPOC): Studi Kasus PT XYZ,” J. Tek. Inform. Univ. Muhammadiyah Tangerang, vol. 2, no. 1, pp. 70-77, 2018.

[4] A. Herdiansah, R. I. Borman, and S. Maylinda, "Sistem Informasi Monitoring dan Reporting Quality Control Proses Laminating Berbasis Web Framework Laravel," J. TEKNO KOMPAK, vol. 15, no. 2, pp. 13-24, 2021

[5] M. Informatika, T. Informatika, A. Karyawan, and B. Web, "Perancangan Sistem Absensi Pegawai Berbasis Web Studi Kasus: Kantor Kecamatan Purwodadi,” J. SWABUMI, vol. 6, no. 2, pp. 184-189, 2018.

[6] R. Ruslan, "Sistem Informasi Absensi Pegawai Berbasis Web Pada Kantor Kelurahan Sako Palembang," J. Sigmata, vol. 9 , no. 1 , pp. 40-49, 2021.

[7] H. Rhomadhona, "Penerapan Teknologi QR Code Berbasis Web untuk Absensi Pegawai pada BKPSDM Kabupaten Tanah Laut," J. Hum. dan Teknol., vol. 4, no. 1, pp. 1-6, 2018.

[8] A. Pulungan, A. Pulungan, and A. Saleh, "Perancangan Aplikasi Absensi Menggunakan QR Code Berbasis Android," J. FTIK, vol. 1, no. 1, pp. 1063-1074, 2019.

[9] D. Alamsyah, "Pengembangan Purwarupa Sistem Proteksi Hybrid Keaslian Faktur Elektronik (E-Invoice) Pada E-Bisnis Menggunakan Qr Code, Steganografi Dan Kriptografi,”J. Tek., vol. 5, no. 2, 2016.

[10] Y. Rahmanto, J. Alfian, and R. I. Borman, "Penerapan Algoritma Sequential Search pada Aplikasi Kamus Bahasa Ilmiah Tumbuhan," J. Buana Inform., vol. 12, no. 1, pp. 21-30, 2021.

[11] A. D. Saputra and R. I. Borman, "Sistem Informasi Pelayanan Jasa Foto Berbasis Android (Studi Kasus: Ace Photography Way Kanan)," J. Teknol. dan Sist. Inf., vol. 1, no. 2, pp. 87-94, 2020.

[12] I. Ahmad, R. I. Borman, J. Fakhrurozi, and G. G. Caksana, "Software Development Dengan Extreme Programming (XP) Pada Aplikasi Deteksi Kemiripan Judul Skripsi Berbasis Android,” J. Invotek Polbeng - Seri Inform., vol. 5, no. 2, pp. 297 307, 2020.

[13] A. Fatoni and D. Dwi, "Rancang Bangun Sistem Extreme Programming Sebagai Metodologi Pengembangan Sistem," Prosisko, vol. 3, no. 1, pp. 1-4, 2016.

[14] R. I. Borman, A. T. Priandika, and A. R. Edison, "Implementasi Metode Pengembangan Sistem Extreme Programming (XP) pada Aplikasi Investasi Peternakan,” JUSTIN (Jurnal Sist. dan Teknol. Informasi), vol. 8, no. 3, pp. 272-277, 2020.

[15] I. Mahendra and D. T. E. Yanto, "Agile Development Methods Dalam Pengembangan Sistem Informasi Pengajuan Kredit Berbasis Web (Studi Kasus : Bank Bri Unit Kolonel Sugiono),” J. Teknol. Dan Open Source, vol. 1, no. 2, pp. 13-24, 2018.

[16] I. Carolina and A. Supriyatna, "Penerapan Metode Extreme Programming Dalam Perancangan Aplikasi Perhitungan Kuota SKS Mengajar Dosen,” J. Khatulistiwa Inform., vol. 3, no. 1, pp. 106-113, 2019. 
Building of Informatics, Technology and Science (BITS)

Volume 3, No 3, December 2021, Page 164-170

ISSN 2684-8910 (media cetak)

ISSN 2685-3310 (media online)

DOI 10.47065/bits.v3i3.1018

[17] L. Rusdiana, "Extreme Programming untuk rancang bangun aplikasi pengelolaan surat keterangan kependudukan," Regist. J. Ilm. Teknol. Sist. Inf., vol. 4, no. 1, p. 49, 2018.

[18] E. B. Pratama, "Pendekatan Metodologi Extreme Programming pada Aplikasi e-Commerce Berbasis M-Commerce Studi Kasus: Toko Buku An'Nur di Pontianak," J. Khatulistiwa Inform., vol. V, no. 2, pp. 92-102, 2017.

[19] R. D. Gunawan, R. Napianto, R. I. Borman, and I. Hanifah, "Penerapan Pengembangan Sistem Extreme Programming Pada Aplikasi Pencarian Dokter Spesialis di Bandar lampung Berbasis Android," J. Format, vol. 8, no. 2, pp. 148-157, 2019.

[20] D. H. Pertiwi, "Metode Extreme Programming (XP) Pada Website Sistem Informasi Franchise LKP Palcomtech," J. Mikrotik, vol. 8, no. 1, pp. 86-98, 2018.

[21] T. Monica and R. I. Borman, "Implementasi Konsep Media Sosial Dalam Sistem Informasi Kegiatan Kesiswaan (Studi Kasus : SMK XYZ),” J. Tekno Kompak, vol. 11, no. 2, pp. 33-37, 2017.

[22] R. I. Borman, K. Syahputra, J. Jupriyadi, and P. Prasetyawan, "Implementasi Internet of Things pada Aplikasi Monitoring Kereta Api dengan Geolocation Information System," in Seminar Nasional Teknik Elektro 2018, 2018, pp. 322-327.

[23] R. D. Gunawan and R. Napianto, "Implementation of Dijkstra ' S Algorithm in Determining the Shortest Path (Case Study: Specialist Doctor Search in Bandar Lampung)," Int. J. Inf. Syst. Comput. Sci., vol. 3, no. 3, pp. 98-106, 2019. 